\title{
Chain End-Functionalized Polymer Brushes with Switchable Fluorescence Response
}

\author{
Sinem Tas, * Maciej Kopeć, Rianne van der Pol, Marco Cirelli, Ilse de Vries, \\ Deniz A. Bölükbas, Kristianne Tempelman, Nieck E. Benes, Mark A. Hempenius, \\ G. Julius Vancso, and Sissi de Beer
}

\begin{abstract}
Herein is described the switchable fluorescence response of poly(methyl methacrylate) (PMMA) brushes. Chain end fluorescein labeled PMMA brushes are prepared by combining surface-initiated atom transfer radical polymerization (SI-ATRP) with a copper-catalyzed alkyne-azide cycloaddition (CuAAC) click reaction. Successful attachment of fluorescein is confirmed by measuring fluorescence of the as-prepared films. Utilizing co-solvency of PMMA in isopropanol-water mixtures, responsive behavior of the end-functionalized brushes is demonstrated by measuring the changes in fluorescence intensity between the swollen and collapsed states.
\end{abstract}

\section{Introduction}

Dye labeling of polymers at specific sites in the chain is a versatile method to follow various physicochemical and optical phenomena occurring at the nanoscale. ${ }^{[1-3]}$ For example, fluorescent dye-labeled polymers have been used to study polymer chain dynamics in solution, ${ }^{[4-6]}$ local glass transition temperature of block copolymers, ${ }^{[7]}$ and structures of block copolymer micelles. ${ }^{[8]}$ Localization of the dye at the chain-end of the polymer backbone can offer advantages including minimally affected intrinsic polymer properties (such as solubility and conformation), minimum self-quenching between closely located dyes, and the binding possibility of recognition molecules in

Dr. S. Tas, Dr. M. Kopeć, R. van der Pol, M. Cirelli, I. de Vries,

Dr. M. A. Hempenius, Prof. G. J. Vancso, Dr. S. de Beer

Materials Science and Technology of Polymers

MESA+ Institute for Nanotechnology

University of Twente

7500 AE, Enschede, The Netherlands

E-mail: s.tas@utwente.nl

Dr. D. A. Bölükbas

Lund University

Department of Experimental Medical Sciences

Lung Bioengineering and Regeneration

22362 Lund, Sweden

K. Tempelman, Prof. N.E. Benes

Membrane Science and Technology

MESA+ Institute for Nanotechnology

University of Twente

7500 AE, Enschede, The Netherlands

The ORCID identification number(s) for the author(s) of this article can be found under https://doi.org/10.1002/macp.201800537.

DOI: 10.1002/macp.201800537 side chains. ${ }^{[1]}$ Thus, chain-end labeling of polymers with a dye is anticipated to be a promising route to incorporate chemicaland bio-sensing functionality in polymerbased surface coatings.

End anchoring of polymer chains at a high density to a surface to form polymer brushes is a powerful way to prepare functional coatings. ${ }^{[9-15]}$ Fluorescent dye-labeled polymer brushes have been prepared and utilized in ion ${ }^{[16-18]}$ sensing and organic light emitting diode (OLED) development ${ }^{[19-21]}$ or in studying the degrafting kinetics of brushes. ${ }^{[2]}$ In this context, responsive polymer brushes, which undergo conformational change upon certain, for example, $\mathrm{pH}$, temperature, ionic strength, and solvent have been modified with fluorescent probes and widely used in the design of sensors. ${ }^{[3,23-26]}$ These polymer brushes are able to change their fluorescence characteristics upon exposure to the stimuli. The thermo- and $\mathrm{pH}$-responsive polymer brushes bearing fluorescent dyes were successfully employed as $\mathrm{pH}^{[23,24]}$ and temperature sensors. ${ }^{[25]}$ Another work on stimuli-responsive fluorescent behavior of polymer brushes included pressure-driven fluorescence response of mechanoresponsive polyelectrolyte brushes. ${ }^{[26]}$

To date, most fluorescently labeled polymer brushes have been prepared by functionalizing side chains with dye molecules as a post-polymerization step, ${ }^{[17,20,22,27]}$ by copolymerization with a fluorescent monomer ${ }^{[16,25,28,29]}$ or by self-assembly of charged fluorescent molecules on charged polymer brushes by electrostatic interactions. ${ }^{[30]}$ One disadvantage of these techniques is that physicochemical properties of the system such as swelling, crystallinity, or wettability are strongly altered by the introduction of a dye, which limits the applicability.

Moreover, densely packed dyes can aggregate and undergo self-quenching leading to a decrease in the fluorescence quantum yield. ${ }^{[31,32]}$ Selective labeling at chain-ends may reduce dye interactions and aggregate formation while keeping the physicochemical properties of the polymer largely intact. So far, only a limited number of studies have reported chainend functionalization of polymer brushes with fluorescent labels. These include converting alkyl bromide end groups into amines before reacting with isothiocyanate-functionalized dye ${ }^{[33]}$ as well as nitroxide radical exchange during polymerization. ${ }^{[19]}$ A straightforward alternative to these synthetic routes could be "click chemistry," which was previously used to modify 
chain-ends of polymer brushes with, for example, recognition elements, ${ }^{[34-37]}$ DNA, ${ }^{[38]}$ and polyethylene glycol (PEG). ${ }^{[39]}$

Here we present switchable fluorescent response of chain end dye-functionalized poly(methyl methacrylate) (PMMA) polymer brushes utilizing co-solvency effect displayed by PMMA in alcohol-water mixtures. ${ }^{[40-42]}$ PMMA brushes is solventresponsive and quality of the solvent determines the conformational state of these brushes. Under good solvent conditions, PMMA brushes are swollen and it collapses upon exposure to poor solvent. ${ }^{[40-42]}$ The chain-ends of poly(methyl methacrylate) (PMMA) brushes modified with an alkynylated fluorescein derivative (FAM alkyne, 5-isomer) by combining surfaceinitiated atom transfer radical polymerization (SI-ATRP) with copper-catalyzed alkyne-azide cycloaddition (CuAAC) click reaction, which greatly simplifies the synthesis of dye chain end functionalized brushes compared to the previously used methods. The chain end modified PMMA brushes exhibited reversible and reproducible fluorescence response.

\section{Experimental Section}

\subsection{Materials}

Methyl methacrylate (MMA, 99\%) was passed through a basic alumina column to remove the inhibitor before use. Copper (I) bromide ( $\mathrm{CuBr}$, Aldrich, 98\%) was stirred in excessive acetic acid and filtered till the suspension solution was light yellow, and was dried in vacuum oven at room temperature overnight. 2,2'-Bipyridyl ( $\geq 99 \%)$, MMA (99\%), sodium azide ( $\geq 99 \%)$, tetrabutylammonium fluoride (TBAF) solution chlorodimethylhydrosilane (98\%), allyl 2-bromo-2-methyl propionate (98\%), and $N, N, N^{\prime}, N^{\prime \prime}, N^{\prime \prime}$-Pentamethyldiethylenetriamine (PMDETA, $99 \%)$ were purchased from Sigma-Aldrich, and used as received without any purification. Alkynylated fluorescein (FAM alkyne, 5-isomer) was purchased from Lumiphore. All solvents were of high purity, and deionized water from a Milli-Q purification system (Millipore Advantage A10) was used throughout the study.

\subsection{Substrate Preparation}

Silicon and glass substrates were cleaned by piranha solution $\left(\mathrm{H}_{2} \mathrm{SO}_{4}: \mathrm{H}_{2} \mathrm{O}_{2}, 3: 1 \mathrm{v} / \mathrm{v}\right)$, then rinsed extensively with water, ethanol and dried using a nitrogen stream (piranha solution reacts with organic compounds and should be handled with extreme caution).

\subsection{Synthesis of PMMA Brushes}

Organosilane initiator was synthesized via hydrosilylation of allyl-2-bromo-methylpropionate with dimethylchlorosilane catalyzed by choloplatinic acid forming (3-(2-bromoisobutyryl) propyl)dimethylchlorosilane (BDCS), as previously reported. ${ }^{[43,44]}$ A monolayer of BDCS was deposited on clean substrates by vapor deposition in a desiccator under vacuum for $24 \mathrm{~h}$, which was followed by atom transfer radical polymerization (ATRP) of methyl methacrylate (MMA) at room temperature for $2 \mathrm{~h}$ under nitrogen. MMA (17.6 g, $176 \mathrm{mmol}$ ) was dissolved in the ATRP medium (methanol: deionized water, $13.8 \mathrm{~mL}: 3.8 \mathrm{~mL}$, $430 \mathrm{mmol}: 210 \mathrm{mmol}$ ) and the solution was degassed before pouring into the Schlenk flask with $\mathrm{CuBr}$ (516 mg, $3.56 \mathrm{mmol}$ ), and 2,2'-bipyridine (1.11 g, $7.11 \mathrm{mmol})$ under nitrogen atmosphere. After stirring for $15 \mathrm{~min}$, the ATRP mixture was transferred to the nitrogen-filled vials with the initiator-coated substrates. ${ }^{[7]}$ After polymerization, the substrates were rinsed with ethanol and water, and dried under nitrogen.

\subsection{Functionalization of PMMA Brush Chain Ends with Fluorescein Via Click Chemistry}

In a round bottom flask, $97.5 \mathrm{mg}(1.5 \mathrm{mmol})$ sodium azide was added to $36 \mathrm{~mL}$ of dimethylformamide (DMF). The solution was then purged for 20 min with nitrogen. Next, the solution was transferred into a flask containing PMMA brush functionalized substrates, which was beforehand sealed with a rubber septum and purged with nitrogen for $20 \mathrm{~min}$. After $24 \mathrm{~h}$ of reaction, the substrates were rinsed extensively with DMF, ethanol and water, and dried under a stream of nitrogen. $10.7 \mathrm{mg}$ (0.26 mmol) alkynylated fluorescein, $29.2 \mathrm{mg}(0.12 \mathrm{mmol}) \mathrm{CuBr}$ and $2.5 \mu \mathrm{L}$ (0.12 mmol) PMDETA were added to $36 \mathrm{~mL}$ DMF and the solution was purged with nitrogen for $20 \mathrm{~min}$. For the click reaction between alkynylated fluorescein and azideterminated polymer brush, the solution was transferred into a flask containing azide chain-end functionalized PMMA brush substrates, which was also purged with nitrogen for $20 \mathrm{~min}$. The click reaction was performed at room temperature under nitrogen atmosphere for $24 \mathrm{~h}$. Afterward, the substrates were rinsed extensively with DMF, ethanol, and water to remove the unreacted dye. The samples were then dried under a stream of nitrogen and kept in dark.

\subsection{Degrafting of PMMA Brush Layer}

To determine the grafting density, PMMA brushes were degrafted from the surface using TBAF. ${ }^{[45,46]} \mathrm{Si}$ wafers grafted with 40-45 nm PMMA brushes were put in flask containing $0.1 \mathrm{M}$ TBAF in $5.5 \mathrm{~mL}$ tetrahydrofuran (THF). The samples were kept stirring at $55^{\circ} \mathrm{C}$ for $24 \mathrm{~h}$. After $24 \mathrm{~h}$, the substrates were rinsed with THF, toluene, water and ethanol, and dried under a stream of nitrogen. THF was evaporated and the polymer sample was then re-dissolved in THF for gel permeation chromatography (GPC). Before and after degrafting, dry brush thickness on the substrate was measured using ellipsometry. After degrafting, the thickness decreased to $0.3 \mathrm{~nm}$, which indicates virtually complete detachment of the brushes.

The conformation of the polymer brush is mainly governed by the interplay between $M n$ and the grafting density $\left(\sigma_{\mathrm{p}}\right) \cdot{ }^{[4]} \sigma_{\mathrm{p}}$ is difficult to determine directly; however, it can be calculated by using the known values of dry polymer thickness $\left(h_{\mathrm{p}}\right)$ and $M_{\mathrm{n}}$ :

$\sigma_{p}=\frac{N_{A} \rho h_{p}}{M_{n}}$ 
In Equation (1), $N_{\mathrm{A}}$ is Avogadro's number and $\rho$ is the bulk density of the polymer. Using Equation (1), $\sigma_{\mathrm{p}}$ was determined as $1.13 \mathrm{~nm}^{-2}$.

\subsection{Characterization}

Dry film thicknesses of the PMMA brushes were measured by spectroscopic ellipsometry (M2000, J.A. Woollam Co., Inc). The ellipsometric data were fit to determine the dry thickness of the polymer brush layer. Optical dispersion (n) can be modelled with a Cauchy dispersion model.

$n(\lambda)=A+\frac{B}{\lambda^{2}}+\frac{C}{\lambda^{4}}$

where $n$ is the refractive index, $A, B$, and $C$ are the Cauchy parameters that can be determined by fitting the equation to measured refractive indices at known wavelengths. A threelayer model consisting of a silicon substrate, a silicon oxide layer, and a Cauchy layer (representing PMMA layer) was used to simulate the experimental data. The thickness $d$ and the Cauchy parameters $A$ and $B$ were used as fitting parameters. Brush swelling measurements were done using atomic force microscopy (AFM) experiments. The AFM setup consisted of a Multimode 8 (Bruker), with a NanoScope V (Veeco) controller, and a JV vertical engage scanner. A scratch was made on the sample to reveal the bare silicon wafer in order to be able to measure the relative height between the brush and the bare silicon. The sample was freshly prepared and the same isopropanol-water mixture solutions were used as in the ellipsometry measurements. For each measurement, images were obtained over a scan size of 30.0 by $15.0 \mu \mathrm{m}$ with a scan rate of $0.300 \mathrm{~Hz}$. First, the relative height of the dry brush in atmospheric conditions was measured in tapping mode using Olympus cantilevers (silicon probe, resonance frequency around $70 \mathrm{kHz}$, force constant around $2 \mathrm{~N} \mathrm{~m}^{-1}$, diameter of tip approximately $9 \mathrm{~nm}$, coated with an aluminum reflecting layer). Second, the relative heights were measured immersed in the different isopropanol-water mixtures by imaging the brush under a low normal load $(<1 \mathrm{nN})$ in contact mode using a colloid probe in a glass liquid cell (Bruker). A polystyrene colloid, $5 \mu \mathrm{m}$ in diameter, was attached onto a MikroMasch HQ line cantilever, the HQ:NSC35/Pt. By thermal noise analysis the spring constant was calculated to be $0.3 \pm 0.03 \mathrm{~N} \mathrm{~m}^{-1}$ at room temperature and ambient conditions. In each obtained image, the relative height is measured at six different positions and an average is taken and used for further calculations. GPC was performed on a Waters system (refractometer: Waters 410, viscometer: Viscotek H502, column: Yst 10E5+10E4+10E3+500 A column set) with DMF $50 \mathrm{~mm} \mathrm{LiCl}$ as eluent. Molecular weights were calculated using linear PMMA standards. Vacuum infrared absorbance spectrum measurements were conducted on Alpha-P Bruker device. Background measurements were performed on a bare silicon wafer to act as a reference. For all the measurements, an average of 256 scans was taken. Fluorescence spectra were measured using a PerkinElmer LS55 spectrofluorometer. Excitation and emission slits were set to a $4.0 \mathrm{~nm}$ and $2.5 \mathrm{~nm}$ band pass, respectively. FAM alkyne, 5-isomer fluorescence was excited at $488 \mathrm{~nm}$. Fluorescence experiments were performed on Nikon A1 confocal microscope equipped with a piezo stage, controller, DU4 multidetector, and LU4 multilaser. 60x contact objective (oil, MRD01691, $2.481 \mu \mathrm{m} \mathrm{px}^{-1}$ and 10x air objectives (MRH00101, $0408 \mu \mathrm{M} \mathrm{px}^{-1}$ ). The samples were illuminated by a $488 \mathrm{~nm}$ laser. Images were acquired by using a constant set of parameters for each sample. Image processing was done with Image J 1.52a software.

\section{Results and Discussion}

The synthetic route to end-labeled PMMA brushes is shown in Scheme 1. First, the initiator (3-(2-bromoisobutyryl) propyl) dimethylchlorosilane (BDCS) is coupled to the silicon surface by vapor deposition. PMMA brushes are then grafted from the initiator-modified surface by surface-initiated atom transfer radical polymerization (SI-ATRP), ${ }^{[10-12]}$ utilizing a previously published procedure (step 1 in Scheme 1). ${ }^{[45,46]}$ Polymerization is followed by measuring the thickness of samples reacted for specific time intervals via ellipsometry (Figure 1A). An initial short period $(1 \mathrm{~h})$ of fast growth is observed before the sufficient amount of deactivator $\left(\mathrm{CuBr}_{2}\right)$ build up in the system, followed by a linear increase of the brush thickness with polymerization time. Samples prepared in $6 \mathrm{~h}$ (i.e., $45 \mathrm{~nm}$-thick) are degrafted from the surface using tetrabutylammonium fluoride ${ }^{[4,46]}$ (TBAF, Figure S1, Supporting Information) and analyzed by gel permeation chromatography (GPC). A symmetric peak with $M_{\mathrm{n}}=25100 \mathrm{~g} \mathrm{~mol}^{-1}$ and narrow molecular weight distribution $\left(M_{\mathrm{w}} / M_{\mathrm{n}}=1.11\right.$, Figure $\left.1 \mathrm{~B}\right)$ is observed, pointing out the excellent control over the surface-initiated polymerization.

For efficient chain end modification, it is critical that the bromide chain end functionality (CEF) remains high after the
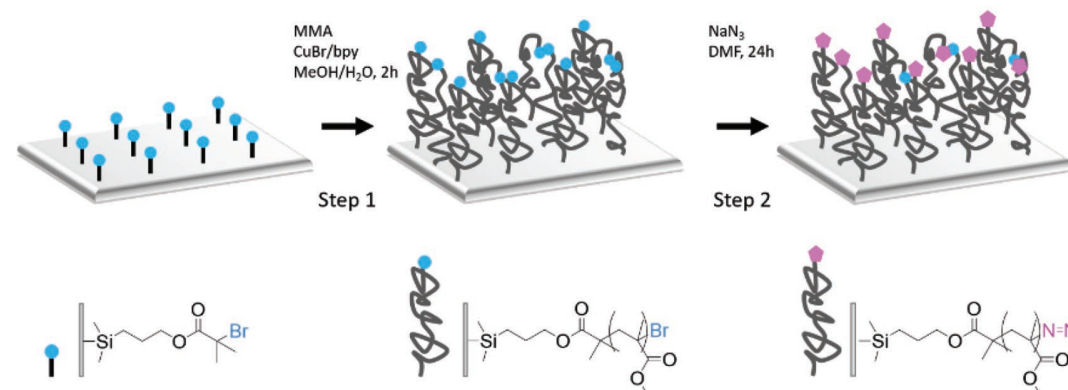

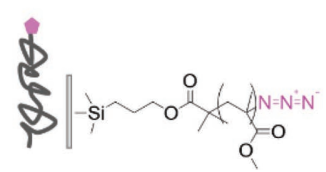

Scheme 1. Synthetic route to end-functionalized fluorescent PMMA brushes. 
A

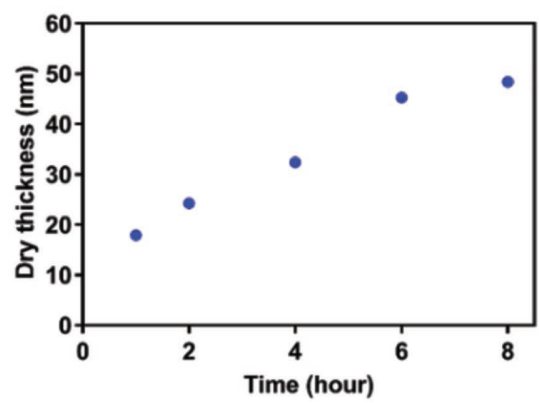

B

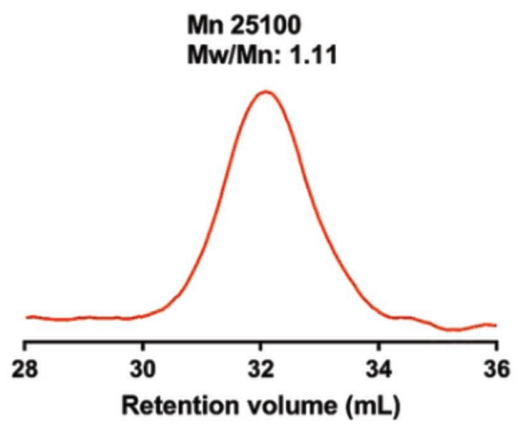

C

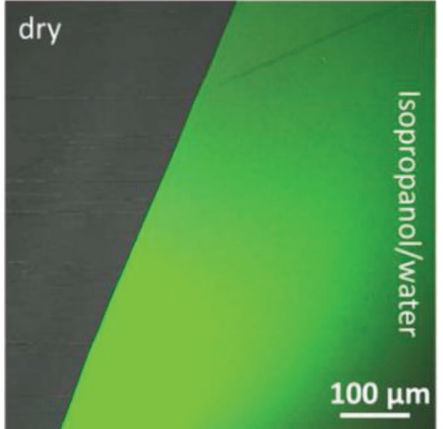

Figure 1. a) Dry thickness of the PMMA brush as a function of polymerization time. b) GPC trace of the brushes, which are synthesized in $6 \mathrm{~h}$ and degrafted by TBAF. c) Fluorescence microscopy image of $25 \mathrm{~nm}$ PMMA-N 3 brushes upon attachment of FAM by click chemistry.

SI-ATRP step. Thus, to ensure that the extent of unavoidable termination events during the polymerization is kept at the lowest possible level, the reaction is stopped before reaching a plateau (visible in the kinetic plot (Figure 1A) at long polymerization times). Hence, a sample prepared in $2 \mathrm{~h}$ (dry thickness $=25 \mathrm{~nm}$ ) is selected for further functionalization by replacing the $\mathrm{Br}$ at the PMMA chain ends with $\mathrm{N}_{3}$ in a reaction with sodium azide (step 2). Finally, the FAM alkyne is attached to the azidefunctionalized PMMA chains by a copper(I)-catalyzed alkyneazide cycloaddition (CuAAC) ("click" reaction, step 3).

Successful attachment of the dye is verified by measuring fluorescence of the as-prepared films. Figure 1C shows a fluorescence microscopy image of fluorescein end-functionalized PMMA brushes in an 80/20 vol.\% isopropanol-water mixture, which is a good solvent for PMMA. ${ }^{[40,41,48,49]}$ Since in this solvent FAM alkyne exhibits excitation and emission maxima around 486 and $524 \mathrm{~nm}$, respectively (Figure S2, Supporting Information), an excitation wavelength of $488 \mathrm{~nm}$ is applied. Clear, green emission is observed confirming efficient functionalization of the chain ends with a fluorescent probe. On the left side of the image, no fluorescent signal is visible due to partial evaporation of the isopropanol-water droplet. As a control, fluorescence of both plain PMMA and PMMA-N $\mathrm{N}_{3}$ brushes, treated with the dye but without the catalyst, are measured (see Figure S3, Supporting Information). Lack of fluorescence for these control surfaces shows that the dye is chemically bonded to the brushes and that its physical adsorption to the surface can be excluded.

Responsive properties of the chain end functionalized fluorescent brushes are demonstrated by studying their behavior while switching the solvent between pure water and $80 / 20$ vol.\% isopropanol-water mixtures. Due to the co-solvency effect displayed by PMMA isopropanol-water mixtures, surfacebound PMMA brushes are collapsed in pure water or isopropanol, but swollen in a mixture of these solvents. ${ }^{[41]}$ Indeed, the dye-functionalized PMMA brushes are measured to swell by approximately $40 \%$ in 80/20 vol.\% isopropanol-water (Figure 2). This swelling ratio is lower than typically observed for PMMA brushes. ${ }^{[40]}$ The reason for this can be the higher grafting density of the brushes in the present work. Alternatively, the dye functionalization might slightly affect the swelling.

Figure 3A shows the fluorescence intensity change of the chain-end functionalized PMMA brushes when the solvent is switched between 80/20 vol.\% isopropanol-water and pure water. The fluorescence intensity under poor solvent conditions (i.e., water) is consistently lower than the fluorescence intensity under good solvent conditions (i.e., 80/20 vol.\% isopropanolwater mixture).

The reason for the lower intensity in pure water is that the brushes are in the collapsed state, forcing the fluorescent dye molecules to aggregate. ${ }^{[50]}$ This leads to self-quenching of the dye molecules as manifested in a weak fluorescent response.

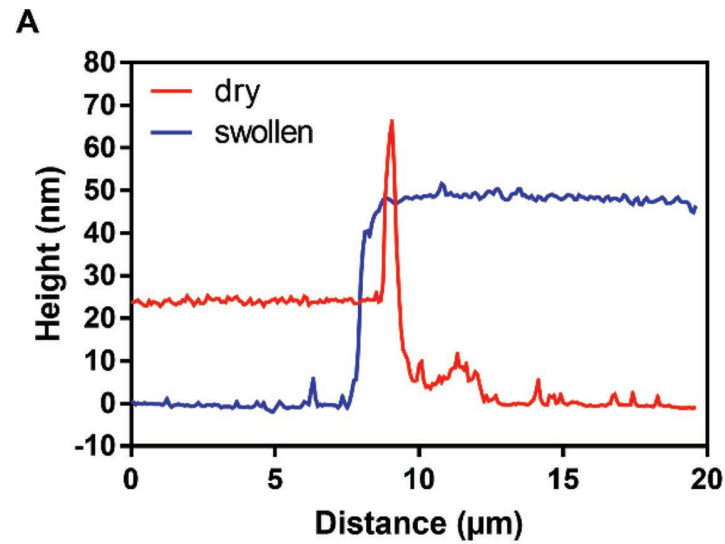

B

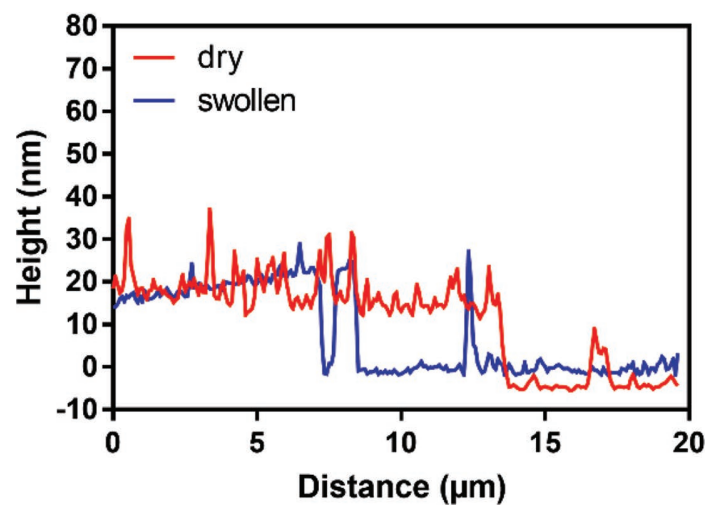

Figure 2. Dry and swollen AFM height of (a) PMMA-Br and (b) PMMAFAM chain-end functionalized brushes in $80 / 20$ vol.\% isopropanol-water mixture. 


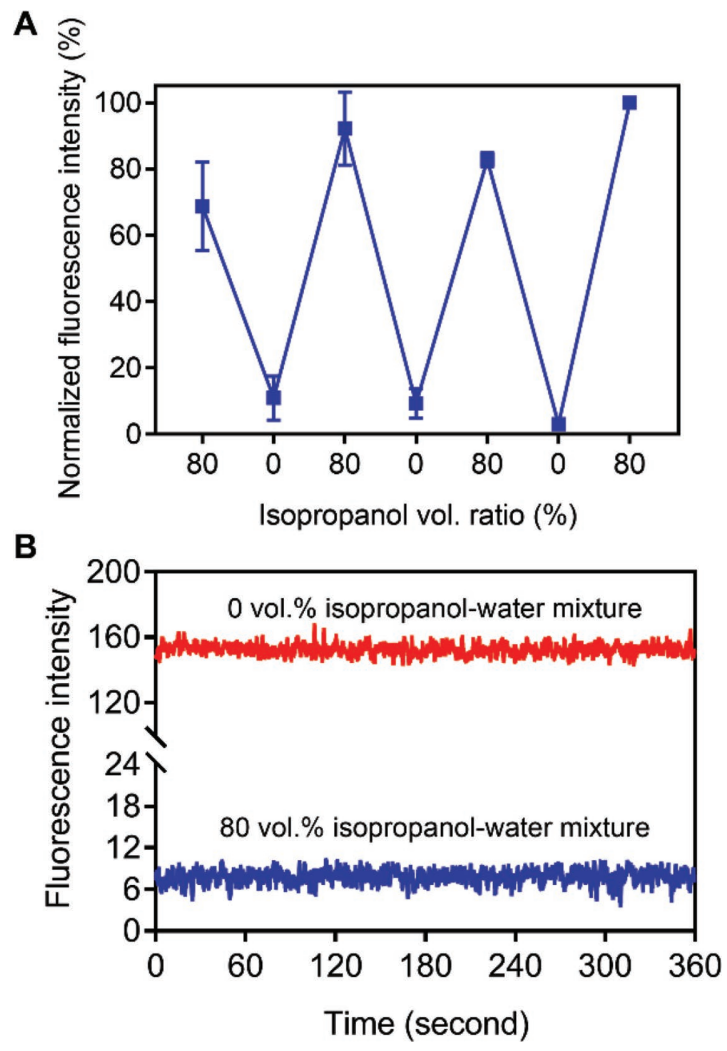

Figure 3. a) Alternating fluorescent intensity after solvent changes from 80 vol.\% isopropanol-water to 0 vol.\% isopropanol-water mixtures, b) solvent-dependent fluorescence intensity of FAM alkyne dye in solution.

In $80 / 20$ vol.\% isopropanol-water, the chain-end functionalized PMMA brushes are swollen and the fluorescein chainends are solubilized by the solvent, displaying clear fluorescent response. Importantly, free fluorescein displays higher emission quantum yields in polar media. ${ }^{[51]}$ Indeed, the fluorescent response of FAM dye in water is measured to be 20x higher than in 80/20 vol.\% isopropanol-water (Figure 3B). Remarkably, no emission from end-labeled PMMA brushes is recorded in pure water, confirming that the fluorescence switching resulted solely from the responsive behavior of the system. In addition, Figure 3B shows that the fluorescence intensity of the dye both in water and 80/20 vol.\% isopropanol-water mixture is stable over a period of $360 \mathrm{~s}$. Thus, the distinct on/off fluorescence response of the brush is only affected by the solvent responsive properties of the chain end functionalized PMMA brushes.

\section{Conclusions}

In summary, we showed switchable fluorescent response of chain end dye-functionalized PMMA polymer brushes. Chainend functionalized fluorescent PMMA brushes were prepared by combining ATRP with click chemistry. Successful synthesis of PMMA and chain-end dye labeled PMMA brushes were confirmed by ellipsometry, AFM, and FTIR. A clear fluorescence response of functionalized PMMA brushes in an 80/20 vol.\% isopropanol-water mixture confirmed the successful attachment of the dye. Switchable fluorescent response was illustrated by utilizing the co-solvency effect displayed by PMMA brushes in isopropanol-water mixtures. Such "smart" macromolecular nanostructures can be employed in the design of future sensors, switchable surfaces or optoelectronic devices.

\section{Supporting Information}

Supporting Information is available from the Wiley Online Library or from the author.

\section{Acknowledgements}

S.T. thanks the University of Twente and the MESA+Institute for Nanotechnology for financial support. M.K. thanks the 4TU.High-Tech Materials research program: 'New Horizons in designer materials' (www.4tu.nl/htm) for financial support and Dr. Karol Wolski (Jagiellonian University) for helpful discussions.

\section{Conflict of Interest}

The authors declare no conflict of interest.

\section{Keywords}

co-solvency, fluorescent polymers, polymer brushes, solvent responsiveness

Received: December 7, 2018 Published online:

[1] M. Beija, M. T. Charreyre, J. M. G. Martinho, Prog. Polym. Sci. 2011, 36, 568.

[2] S. Liu, Y. Cheng, H. Zhang, Z. Qiu, R. T. K. Kwok, J. W. Y. Lam, B. Z. Tang, Angew. Chem., Int. Ed. 2018, 57, 6274.

[3] O. Tagit, N. Tomczak, A. Jafarpour, D. Jańczewski, M. Y. Han, G. J. Vancso, L. J. Herek, Nanotechnology 2011, 22, 265701.

[4] M. Ingratta, J. Hollinger, J. Duhamel, J. Am. Chem. Soc. 2008, 130, 9420.

[5] S. Chen, J. Duhamel, M. A. Winnik, J. Phys. Chem. B 2011, 115, 3289.

[6] J. Yip, J. Duhamel, X. P. Qiu, F. M. Winnik, Macromolecules 2011, 44, 5363.

[7] D. Christie, R. A. Register, R. D. Priestley, ACS Cent. Sci. 2018, 4, 504.

[8] G. Marcelo, T. J. V. Prazeres, M. T. Charreyre, J. M. G. Martinho, J. P. S. Farinha, Macromolecules 2010, 43, 501.

[9] M. Krishnamoorthy, S. Hakobyan, M. Ramstedt, J. E. Gautrot, Chem. Rev. 2014, 114, 10976.

[10] X. Guojun, A. Khabibullin, J. Pietrasik, J. Yan, K. Matyjaszewski, in Polymer and Biopolymer Brushes (Eds: O. Azzaroni, I. Szleifer), Wiley, Hoboken, NJ 2017, Ch. 2.

[11] J. O. Zoppe, N. C. Ataman, P. Mocny, J. Wang, J. Moraes, H.-A. Klok, Chem. Rev. 2017, 117, 1105.

[12] C. M. Hui, J. Pietrasik, M. Schmitt, C. Mahoney, J. Choi, M. R. Bockstaller, K. Matyjaszewski, Chem. Mater. 2014, 26, 745.

[13] S. T. Miller, Science 1991, 251, 905.

[14] W.-L. Chen, R. Cordero, H. Tran, C. K. Ober, Macromolecules 2017, 50, 4089. 
[15] S. Edmondson, V. L. Osborne, W. T. S. Huck, Chem. Soc. Rev. 2004, $33,14$.

[16] X. Wan, S. Yao, H. Liu, Y. Yao, J. Mater. Chem. A 2013, 1, 10505.

[17] P. Qiang, X. Ming-Gui, N. Koon-Gee, K. En-Tang, Chem. Lett. 2005, 34, 1164.

[18] J. Sha, Y. Song, B. Liu, C. Lü, Microporous Mesoporous Mater. 2015, $218,137$.

[19] S. B. Jhaveri, M. Beinhoff, C. J. Hawker, K. R. Carter, D. Y. Sogah, ACS Nano 2008, 2, 719.

[20] Z. A. Page, B. Narupai, C. W. Pester, R. Bou Zerdan, A. Sokolov, D. S. Laitar, S. Mukhopadhyay, S. Sprague, A. J. McGrath, J. W. Kramer, P. Trefonas, C. J. Hawker, ACS Cent. Sci. 2017, 3, 654.

[21] O. Roling, R. K. De Bruycke, B. Vonhören, L. Stricker, M. Körsgen, H. F. Arlinghaus, B. J. Ravoo, F. E. Du Prez, Angew. Chem., Int. Ed. 2015, 54, 13126

[22] O. Borozenko, R. Godin, K. L. Lau, W. Mah, G. Cosa, W. G. Skene, S. Giasson, Macromolecules 2011, 44, 8177.

[23] J. Madsen, R. E. Ducker, O. Al Jaf, M. L. Cartron, A. M. Alswieleh, C. H. Smith, C. N. Hunter, S. P. Armes, G. J. Leggett, Chem. Sci. 2018, 9, 2238

[24] N. Akkilic, R. Molenaar, M. M. A. E. Claessens, C. Blum, W. M. de Vos, Langmuir 2016, 32, 8803

[25] T. Wu, G. Zou, J. M. Hu, S. Y. Liu, Chem. Mater. 2009, 21, 3788.

[26] B. Johanna, E. Johann, B. P. Maarten, F. Andreas, W. T. S. Huck, Angew. Chem., Int. Ed. 2011, 50, 9629.

[27] S. Michał, W. Karol, P. Agata, U. Tomasz, G. Arkadiusz, Ł. Łukasz, Z. Szczepan, Chem. - Eur. J. 2017, 23, 11239.

[28] Y. Song, J. Lu, B. Liu, C. Lu, J. Mater. Chem. C 2016, 4, 7083.

[29] A. Nese, N. V. Lebedeva, G. Sherwood, S. Averick, Y. Li, H. Gao, L. Peteanu, S. S. Sheiko, K. Matyjaszewski, Macromolecules 2011, 44, 5905.

[30] X. Yang, B. Shen, Y. Jiang, Z. Zhao, C. Wang, C. Ma, B. Yang, Q. Lin, J. Mater. Chem. A 2013, 1, 1201.

[31] C. J. Ellison, J. M. Torkelson, J. Polym. Sci., Part B: Polym. Phys. 2002, 40, 2745.
[32] K. Wolski, M. Szuwarzyński, M. Kopeć, S. Zapotoczny, Eur. Polym. J. 2015, 65, 155.

[33] R. Matsuno, K. Ishihara, MRS Proceedings 2008, 1093, CC04.

[34] A. R. Kuzmyn, A. de los Santos Pereira, O. Pop-Georgievski, M. Bruns, E. Brynda, C. Rodriguez-Emmenegger, Polym. Chem. 2014, 5, 4124.

[35] V. Parrillo, A. D. Pereira, T. Riedel, C. Rodriguez-Emmenegger, Anal. Chim. Acta 2017, 971, 78.

[36] E. van Andel, I. de Bus, E. J. Tijhaar, M. M. J. Smulders, H. F. J. Savelkoul, H. Zuilhof, ACS Appl. Mater. Interfaces 2017, 9, 38211.

[37] A. T. Nguyen, J. Baggerman, J. M. J. Paulusse, H. Zuilhof, C. J. M. van Rijn, Langmuir 2012, 28, 604.

[38] J. S. Oh, Y. F. Wang, D. J. Pine, G. R. Yi, Chem. Mater. 2015, 27, 8337.

[39] C. G. Wang, A. Goto, J. Am. Chem. Soc. 2017, 139, 10551.

[40] R. Hoogenboom, C. R. Becer, C. Guerrero-Sanchez, S. Hoeppener, U. S. Schubert, Aust. J. Chem. 2010, 63, 1173.

[41] Y. Yu, B. D. Kieviet, E. Kutnyanszky, G. J. Vancso, S. de Beer, ACS Macro Lett. 2015, 4, 75

[42] D. Mukherji, C. M. Marques, T. Stuehn, K. Kremer, Nat. Commun. 2017, 8, 1374.

[43] R. Iwata, P. Suk-In, V. P. Hoven, A. Takahara, K. Akiyoshi, Y. Iwasaki, Biomacromolecules 2004, 5, 2308.

[44] M. G. Santonicola, G. W. de Groot, M. Memesa, A. Meszyńska, G. J. Vancso, Langmuir 2010, 26, 17513.

[45] R. R. Patil, S. Turgman-Cohen, J. Srogl, D. Kiserow, J. Genzer, Langmuir 2015, 31, 2372.

[46] R. R. Patil, S. Turgman-Cohen, J. Šrogl, D. Kiserow, J. Genzer, ACS Macro Lett. 2015, 4, 251.

[47] E. D. Bain, S. Turgman-Cohen, J. Genzer, Macromol. Theory Simul. 2013, 22, 8

[48] D. Satyanarayana, P. R. Chatterji, Polymer 1993, 34, 3682.

[49] S. M. Lee, Y. C. Bae, Polymer 2014, 55, 4684.

[50] E. M. Benetti, S. Zapotoczny, J. Vancso, Adv. Mater. 2007, 19, 268.

[51] A. Yamada, Y. Hiruta, J. Wang, E. Ayano, H. Kanazawa, Biomacromolecules 2015, 16, 2356. 